\title{
ENHANCEMENT OF THE SOLUBILITY AND THE DISSOLUTION RATE OF TAMOXIFEN CITRATE SOLID DISPERSION USING SOLUPLUS BY SOLVENT EVAPORATION TECHNIQUE
}

\author{
HAYDER HUSSEIN ABDULJABBAR, SHAIMAA NAZAR ABD ALHAMMID*
}

Department of Pharmaceutics, College of Pharmacy, University of Baghdad, Baghdad, Iraq. Email: shaimaapharmakon@gmail.com

Received: 04 August 2018, Revised and Accepted: 17 September 2018

ABSTRACT

Objective: The aim of the present study was the enhancement in the solubility of tamoxifen citrate using solid dispersion which is considered as a great solution to overcome the poor water solubility behavior of tamoxifen citrate (TMX) by solvent evaporation technique using Soluplus ${ }^{\circledR}$ as a novel carrier then formulate it as an orodispersible tablet.

Method: A total of 24 formulas were prepared as a solid dispersion by solvent evaporation method using Soluplus ${ }^{\circledR}$ as a polymeric solubilizer in the ratio of $1: 1,1: 3,1: 5,1: 7$, and 1:10 then formulated as orodispersible tablets by incorporating three types of superdisintegrants; croscarmellose, crospovidone, and sodium starch glycolate (SSG) with the solid dispersion. Characterization of the formulation was done using differential scanning colorimetry, Fourier transforms infrared spectroscopy, X-ray diffraction, and scanning electron microscope and the best formula was selected according to the disintegration and dissolution tests.

Results and Discussion: Formula 22 were selected as the best formula which contains mixed types of superdisintegrants; croscarmellose and SSG with the fastest complete disintegration of $6.5 \mathrm{~s}$ and complete dissolution with $<2 \mathrm{~min}$.

Conclusion: Accordingly, TMX was successfully enhanced its water solubility by converting its crystalline structure into the amorphous state through solid dispersion with Soluplus ${ }^{\circledR}$ and formulated as an orodispersible tablet to improve its oral absorption.

Keywords: Tamoxifen citrate, Solid dispersion, Soluplus ${ }^{\circledR}$, Orodispersible tablet, Superdisintegrants.

(C) 2019 The Authors. Published by Innovare Academic Sciences Pvt Ltd. This is an open access article under the CC BY license (http://creativecommons. org/licenses/by/4. 0/) DOI: http://dx.doi.org/10.22159/ajpcr.2019.v12i1.28933

\section{INTRODUCTION}

One of the most challenging types of cancer is the breast cancer. Therefore, the incidence of it is remarkably rises making it the leading cause of mortality among all other types of cancer worldwide [1]. Tamoxifen citrate (TMX) has been used most commonly for the management of estrogen receptor breast cancer [2]. It is selective estrogen receptor modulator used in the treatment of early and advanced breast carcinoma in postmenopausal women [3].

On oral administration, only a limited amount of TMX is absorbed and reaches the blood circulation due to the low water solubility and an extensive first-pass metabolism [4,5]. Accordingly, there are numerous approaches attempted to overcome those obstacles one of them is by improving their water solubility through a nano sizing method or incorporation with coenzymes to avoid enzymatic degradation by the liver [5]. Solid dispersion is one of the approaches that used to improve the solubility of slightly soluble drugs like tamoxifen citrate since solid dispersion has many advantages like simplicity and low cost [6].

The solid dispersion can be defined as a dispersion of pharmacologically active substance through a matrix system. Usually, an inert carrier can be used which has the ability to disperse the drug in an aqueous medium either by reduce their particle size or convert it to an amorphous form leads to improve the solubility of the drug in water [7].

Many methods have been established to prepare a solid dispersion; solvent evaporation method is the most commonly used for small-scale preparation which include the dissolving both active pharmaceutical ingredient and the carrier in an organic solvent then allowed to evaporate to form a solid dispersion [7,8]. Furthermore, one of the most recent polymers that showed an enormous solubility enhancement is the Soluplus ${ }^{\circledR}$, which is a polyethylene glycol polyvinyl caprolactam acetate grafted copolymer which is a novel thermoplastic internally plasticized amphiphilic polymer made for the preparation of solid dispersion with an excellent solubility enhancement and effective flowability characteristics [9].

To investigate the dissolution properties of TMX, Soluplus will be used to study its water solubility profile using solid dispersion and evaluate its characteristics by Fourier transforms infrared spectroscopy (FTIR), differential scanning colorimetry (DSC), particle properties study, and measurement of phase solubility and dissolution behavior.

\section{MATERIALS AND METHODS}

\section{Materials}

Soluplus ${ }^{\circledR}$ obtained as a gift from BASF, Germany. Crospovidone, croscarmellose (CC), sodium starch glycolate (SSG), mannitol, Avecil G102, and magnesium stearate obtained as a gift from Pioneer Pharmaceutical. TMX was purchased from Shijiazhuang Aopharm Import and Export Trading Co., Ltd.

\section{Methods}

Solid dispersion preparation

Solid dispersions were prepared using the solvent evaporation method with different TMX to Soluplus ratios such as 1:3, 1:5, 1:7, and 1:10.

\section{Solvent evaporation method}

An accurate amount of TMX was dissolved in a suitable amount of methanol, mixed thoroughly until it's completely dissolved, after that, Soluplus ${ }^{\circledR}$ was added to the organic solution and mixed using a magnetic stirrer for about $15 \mathrm{~min}$ then sonicated using an ultrasonicator for 10 
more min to assure complete dissolution. The resultant solution kept overnight in a desiccator for drying [10].

\section{Characterization of TMX and solid dispersion powders \\ Thermodynamic solubility study}

Solubility study was conducted to investigate the apparent solubility of TMX and the solid dispersion powders prepared by a solvent evaporation method. An excess amount of each powder was added to a $5 \mathrm{ml}$ distilled water in a screw-capped sealed container maintained under continuous shaking (200 rpm) and protected from light at room temperature (about $25^{\circ} \mathrm{C}$ ) for $48 \mathrm{~h}$ to achieve an equilibrium. Samples were centrifuged, filtered using $0.45 \mu$ size Millipore and measured spectrophotometrically at $275 \mathrm{~nm}[4]$.

DSC

DSC was performed to examine the thermal behavior of TMX and the solid dispersion powder. The device used was Shimadzu, Japan DSC. A sample of about $5 \mathrm{mg}$ of solid dispersion was packed inside a sealed aluminum pan and heated at a scanning rate of $10^{\circ} \mathrm{C} / \mathrm{min}$ on a temperature range from $25^{\circ} \mathrm{C}$ to $300^{\circ} \mathrm{C}$ [11].

\section{FTIR spectroscopy}

FTIR was conducted to look into any alteration of the crystalline type of TMX after solid dispersion process. A sample of about $1 \mathrm{mg}$ of the drug was grounded then mixed with potassium bromide and compressed through a manual press to form a thin disc and analyzed using FTIR spectroscopy in a range from 4000 to $400 / \mathrm{cm}$ [12].

\section{Powder X-ray diffraction (XRD)}

Diffraction model of TMX plain powder, Soluplus plain powder, and the selected solid dispersion formulation were attempted to determine the degree of crystallinity using (Shimadzu, Japan) X-ray diffractometer by utilizing $\mathrm{Cu} \mathrm{K} \alpha$ radiation with a nickel filter, a voltage of $40 \mathrm{kV}$, and a current of $25 \mathrm{~mA}$. The samples were analyzed in a range from $5^{\circ} \mathrm{C}$ to $50^{\circ} \mathrm{C}[12]$

\section{Scanning electron microscopy (SEM) analysis}

The surface morphology of TMX powder and the selected solid dispersion formula were investigated using electron microscope (Shimadzu, Japan). The samples were mounted on a glass stub and coated with a thin layer of gold under vacuum for about $5 \mathrm{~min}$ in an argon atmosphere before an examination. Micro images with different magnifications were recorded to analyze surface characteristics of the solid dispersions [13].

\section{Powder evaluation}

Flow characteristics of TMX powder and solid dispersions blends Flowability and compressibility are essential powder properties which are required for powder compression into tablets. According to USP pharmacopeia, an angle of repose test is used for measuring flowability of the powder. Furthermore, for compressibility, Hausner's ratio and Carr's index that determined using bulk density and tapped density measurement according to the following equation:

Carr's index $=\rho p-\rho b / \rho p \times 100$

Bulk density represented by $\rho b\left(\mathrm{~g} / \mathrm{cm}^{3}\right)$

Tapped density represented by $\rho p\left(\mathrm{~g} / \mathrm{cm}^{3}\right)$

Hausner's ratio which is calculated according to the following equation:

Hausner's ratio = volume before tapping/volume after tapping.

Flowability determination using the angle of repose test involves the use of a funnel technique in which the powder is allowed to flow throw a funnel of $1 \mathrm{~cm}$ in diameter and poured into a flat horizontal plate. The angle of repose then determined using the following equation:

$\operatorname{Tan} \theta=\mathrm{h} / \mathrm{r}$

In which, $\mathrm{H}$ is the tip height of the funnel from the surface plate and $\mathrm{R}$ is the radius of the circle that drawn around the powder pile [14].

\section{Orodispersible tablet preparation}

According to the solubility analysis, the optimized solid dispersion powders were selected and compressed into an orodispersible tablet and evaluated for further investigation. Different types of super disintegrants were used at different ratios as shown in Table 1; croscarmellose, crospovidone, and SSG. The compression of powder was made using a manual single punch press of $9 \mathrm{~mm}$ die and the tablets formed with a hardness of $4 \pm 0.5 \mathrm{~kg}$.

\section{Orodispersible tablet evaluation}

\section{In vitro disintegration time}

The disintegration time of the prepared orodispersible tablet was done through USP standard specified test. One tablet was held in a six holes basket and immersed in $900 \mathrm{ml}$ phosphate buffer 6.8 in a fixed motion of raising and lowering at $30 \mathrm{cycles} / \mathrm{min}$ at $37.5^{\circ} \mathrm{C}$. The time for complete disintegration of tablets was measured and recorded [15].

\section{In vitro dissolution time}

The dissolution of TMX was carried out using USP apparatus II, the paddle method, in $900 \mathrm{ml}$ of 6.8 phosphate buffer at $37.5^{\circ} \mathrm{C}$ and the rotation speed of the paddle was $50 \mathrm{rpm}$ using (Pharmatest, Germany). A $5 \mathrm{ml}$ samples were with drown at time intervals of 2, 4, 6, 8, 10,15, 20, 25 , and $30 \mathrm{~min}$ and replaced with $5 \mathrm{ml}$ of fresh dissolution medium for maintaining saturation solubility. The samples then filtered using 0.45 filter syringes and analyzed spectrophotometrically at $275 \mathrm{~nm}[16,17]$.

\section{Statistical analysis}

The results of the experiments are given as a mean of triplicate samples \pm standard deviation and were analyzed according to the t-test at the level of $\mathrm{p}<0.05$ [18].

\section{RESULTS AND DISCUSSION}

Thermodynamic solubility study

The intrinsic solubility of TMX and its solid dispersion formulas were obtained and presented in Fig. 1. The results showed that there was a significant increase in the solubility of TMX by solid dispersion. A gradual water solubility increase as the concentration of Soluplus increased. For $1: 3$ ratio there is a small increase in water solubility when compared to $1: 7$ and $1: 10$ ratios and that could be due to that at a lower concentration of the carrier, a higher amount of TMX was not incorporated within the carrier. On the other hand, with a higher concentration of the carrier, a larger amount of TMX dispersed within the Soluplus and improved its wettability. At 1:1 ratio, it presented a paradoxical effect of decreasing in water solubility less than the pure drug. This can be explained due to the glass suspension of solid dispersion and formation of a viscous layer that delay the hydration of TMX particle [19].

\section{DSC}

The thermal behavior of TMX and solid dispersion was obtained and presented a sharp peak at $147^{\circ} \mathrm{C}$ for TMX as shown in Fig. 2 . On the contrary, the widening of this peak with solid dispersion formula indicates the conversion of TMX crystals into an amorphous incorporated with soluplus.

\section{FTIR}

The results were obtained and showed a characteristic peak of TMX, Soluplus, and the selected solid dispersion formula. For TMX, it shows a sharp peak at $3080 / \mathrm{cm}$ for the aromatic (C-H) stretching, at $1124 / \mathrm{cm}$ for (C-O) stretching of ether, at $1704 / \mathrm{cm}$ for carbonyl stretching of carboxyl in dimmer, and at $2964 / \mathrm{cm}$ for the hydroxyl stretching of carboxylate. On the other hand soluplus, showed well-defined characteristic peaks 
Table 1: Solid dispersion formulas composition prepared by solvent evaporation technique

\begin{tabular}{|c|c|c|c|c|c|c|c|c|c|c|c|c|}
\hline \multirow[t]{2}{*}{ Material (mg) } & \multicolumn{12}{|c|}{ Formula code } \\
\hline & F1 & F2 & F3 & F4 & F5 & F6 & F7 & F8 & F9 & F10 & F11 & F12 \\
\hline SOL (1:3) TMX & 40 & 40 & 40 & 40 & 40 & 40 & & & & & & \\
\hline SOL (1:5) TMX & & & & & & & 60 & 60 & 60 & 60 & 60 & 60 \\
\hline SOL (1:7) TMX & & & & & & & & & & & & \\
\hline SOL $(1: 10)$ TMX & & & & & & & & & & & & \\
\hline Croscarmellose & 10 & & & 5 & 5 & & 10 & & & 5 & 5 & \\
\hline $\begin{array}{l}\text { Sod. Starch } \\
\text { glycolate }\end{array}$ & & 10 & & 5 & & 5 & & 10 & & 5 & & 5 \\
\hline Crospovidone & & & 10 & & 5 & 5 & & & 10 & & 5 & 5 \\
\hline Mg. stearate & 2 & 2 & 2 & 2 & 2 & 2 & 2 & 2 & 2 & 2 & 2 & 2 \\
\hline Avicel PH 102 & 30 & 30 & 30 & 30 & 30 & 30 & 30 & 30 & 30 & 30 & 30 & 30 \\
\hline Citric acid & 10 & 10 & 10 & 10 & 10 & 10 & 10 & 10 & 10 & 10 & 10 & 10 \\
\hline Aspartame & 2 & 2 & 2 & 2 & 2 & 2 & 2 & 2 & 2 & 2 & 2 & 2 \\
\hline \multirow[t]{4}{*}{ Mannitol } & Up to & Up to & Up to & Up to & Up to & Up to & Up to & Up to & Up to & Up to & Up to & Up to \\
\hline & 200 & 200 & 200 & 200 & 200 & 200 & 200 & 200 & 200 & 200 & 200 & 200 \\
\hline & \multicolumn{12}{|c|}{ Formula code } \\
\hline & F13 & F14 & F15 & F16 & F17 & F18 & F19 & F20 & F21 & F22 & F23 & F24 \\
\hline \multicolumn{13}{|l|}{ SOL (1:3) TMX } \\
\hline \multicolumn{13}{|l|}{ SOL (1:5) TMX } \\
\hline SOL (1:7) TMX & 80 & 80 & 80 & 80 & 80 & 80 & & & & & & \\
\hline SOL $(1: 10)$ TMX & & & & & & & 110 & 110 & 110 & 110 & 110 & 110 \\
\hline Croscarmellose & 10 & & & 5 & 5 & & 10 & & & 5 & 5 & \\
\hline \multicolumn{13}{|l|}{ glycolate } \\
\hline Crospovidone & & & 10 & & 5 & 5 & & & 10 & & 5 & 5 \\
\hline Mg. stearate & 2 & 2 & 2 & 2 & 2 & 2 & 2 & 2 & 2 & 2 & 2 & 2 \\
\hline Avicel PH 102 & 30 & 30 & 30 & 30 & 30 & 30 & 30 & 30 & 30 & 30 & 30 & 30 \\
\hline Citric acid & 10 & 10 & 10 & 10 & 10 & 10 & 10 & 10 & 10 & 10 & 10 & 10 \\
\hline Aspartame & 2 & 2 & 2 & 2 & 2 & 2 & 2 & 2 & 2 & 2 & 2 & 2 \\
\hline \multirow[t]{2}{*}{ Mannitol } & Up to & Up to & Up to & Up to & Up to & Up to & Up to & Up to & Up to & Up to & Up to & Up to \\
\hline & 200 & 200 & 200 & 200 & 200 & 200 & 200 & 200 & 200 & 200 & 200 & 200 \\
\hline
\end{tabular}

SOL referred to Soluplus, TMX referred to tamoxifen citrate

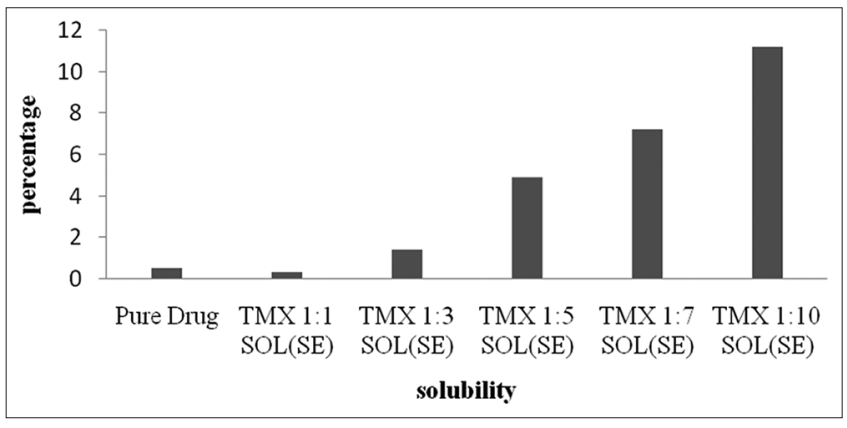

Fig. 1: The solubility in water of TMX and solid dispersion powder with Soluplus ${ }^{\circledR}$ prepared by the solvent evaporation method presented in $\mathrm{mg} / \mathrm{ml}$

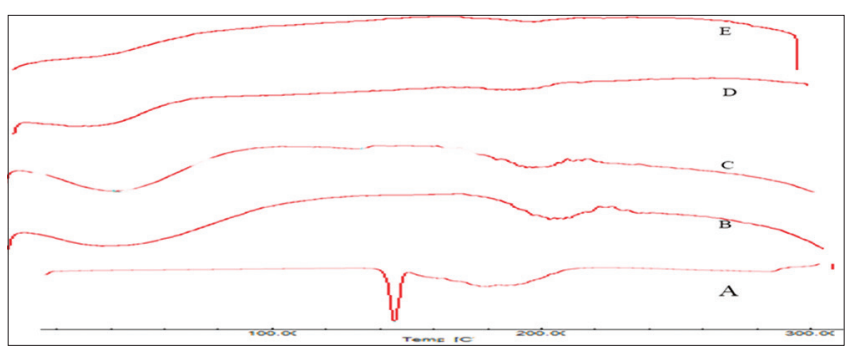

Fig. 2: (a) Thermal behavior of tamoxifen citrate, (b) 1:3 solid dispersion, (c) 1:5 solid dispersion, (d) 1:7 solid dispersion, and (e) 1:10 solid dispersion which are; $3439 \mathrm{~cm}^{-1}$ for (OH) stretching group, $2932 \mathrm{~cm}^{-1}$ for aromatic (CH) stretching group, $1736 \mathrm{~cm}^{-1}$ and $1638 \mathrm{~cm}^{-1}$ for carbonyl stretching group and $1478 \mathrm{~cm}-1$ for (C-O-C) stretching group.The solid dispersion showed a shifting $(\mathrm{OH})$ stretching group to $3460 \mathrm{~cm}-1$ due to a possible hydrogen bonding $[20,14]$. The solid dispersion showed a shifting $(\mathrm{OH})$ stretching to $3460 / \mathrm{cm}$ due to possible hydrogen bonding [5,14] (Fig. 3).

\section{Powder XRD}

The results showed strong sharp peaks of TMX which are contributed to the higher degree of crystalline nature of its powder. The peaks of the solid dispersion were remarkably disappeared, due to the conversion of TMX from a crystalline state to an amorphous state. On the other hand in the physical mixture, peak intensities are clearly weaken when it compared to TMX alone but still present which indicates the presence of TMX crystals remaining in crystalline form (Fig. 4) [20].

\section{SEM analysis}

The results of SEM are illustrated in Fig. 5. The surface morphology of TMX showed a cluster of clear crystals indicates its crystallinity nature. On the contrary, the solid dispersion showed a smooth homogeneous surface characteristic as one piece and TMX losses its crystalline shape which indicated the conversion to an amorphous state by a solid dispersion [20].

\section{Micromeritic powder evaluation}

The result of the flow properties of powder is presented in Table 2. It can be seen that pure drug has poor powder flowability and compressibility features which significantly enhanced by solid dispersion through solvent evaporation method. 


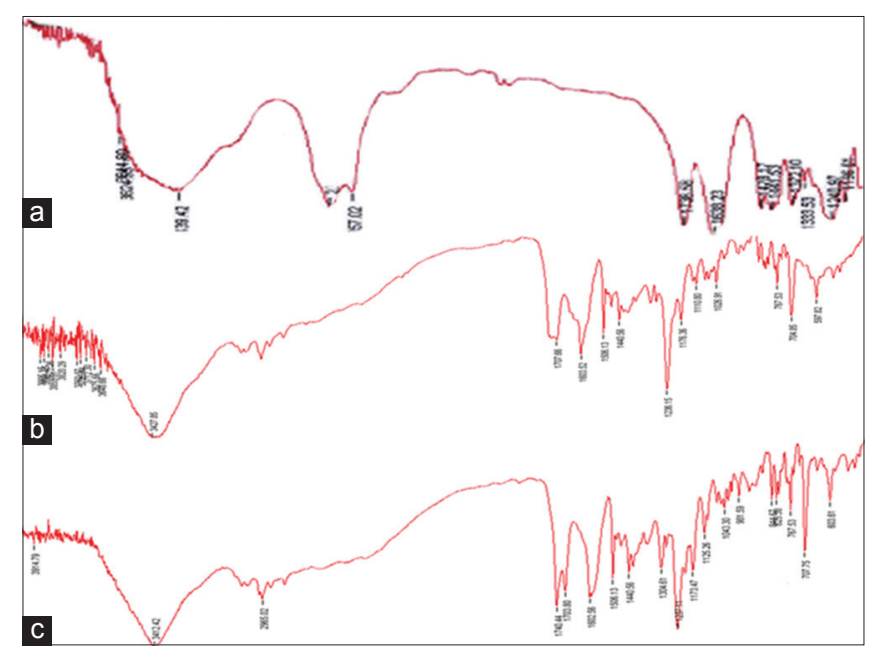

Fig. 3: (a) Is the Fourier transforms infrared spectroscopy of Soluplus ${ }^{\circledR}$, (b) for tamoxifen citrate, and (c) for the selected solid dispersion formula

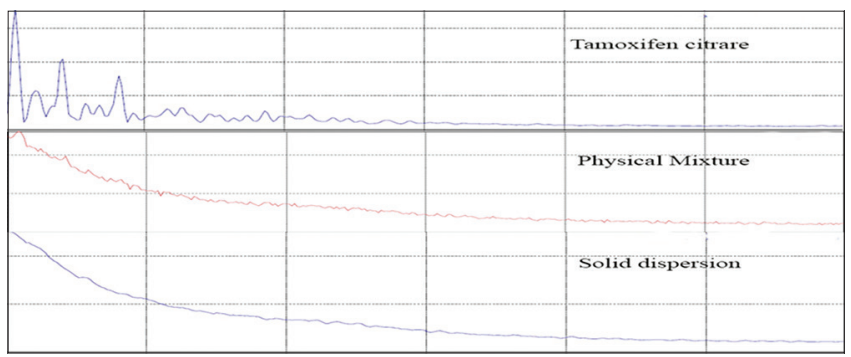

Fig. 4: Powder X-ray diffraction for tamoxifen citrate pure powder, physical mixture, and the selected solid dispersion

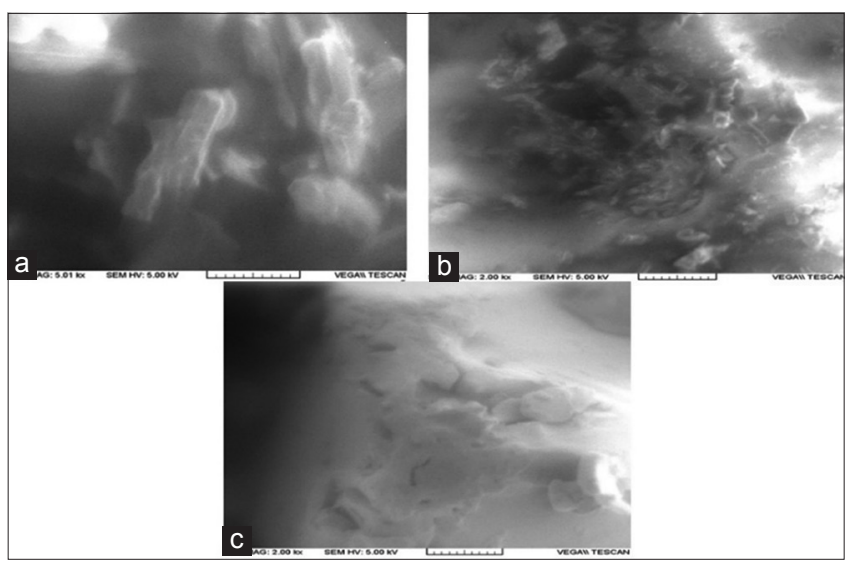

Fig. 5: (a). Scanning electron microscopy (SEM) of tamoxifen citrate, (b) SEM of physical mixture, and (c) SEM of selected solid dispersion

\section{Orodispersible tablet evaluation}

\section{In vitro disintegration time}

Time for complete disintegration is calculated and presented in Table 3. The results revealed that among all formulas which contain $10 \%$ of superdisintegrant, CC showed the shorter disintegration time which is contributed to its high swelling capacity due to hydrophilic, high absorbent nature, and an excellent wicking mechanism contributed to its fibrous nature [21].

On the other hand, among all formulas which contain 5\% mixed of two type's superdisintegrant CC with SSG combination showed the

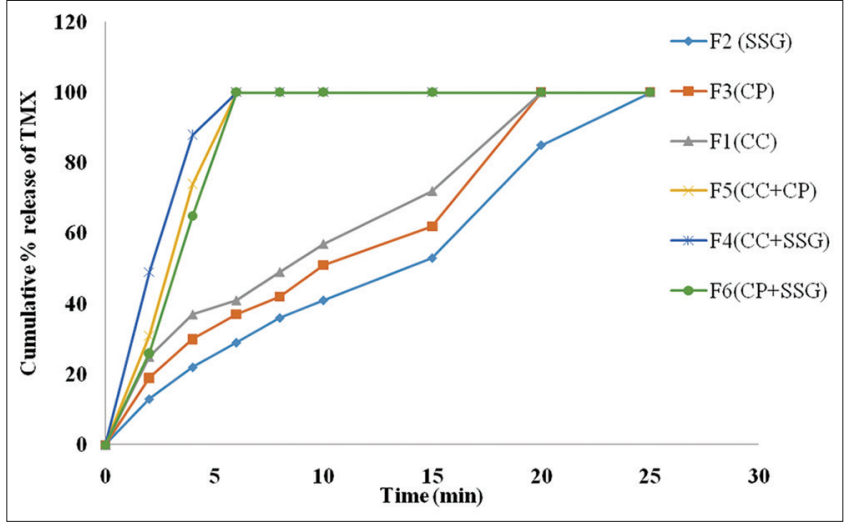

Fig. 6: Dissolution release profile of 1:3 solid dispersion formulas (F1-F6) orodispersible tablets in 6.8 phosphate buffer at $37.5^{\circ} \mathrm{C}$ (Where CC is the croscarmellose, SSG is the sodium starch glycolate, and $\mathrm{CP}$ is the crospovidone)

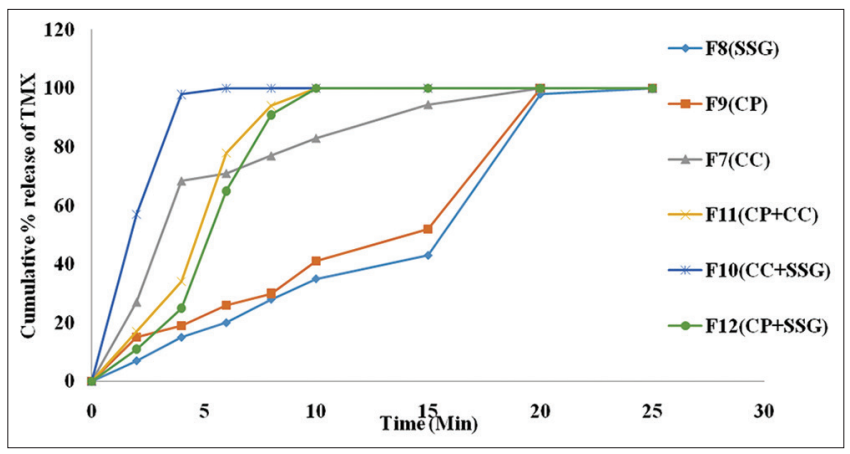

Fig. 7: Dissolution release profile of 1:5 solid dispersion formulas (F8-F12) orodispersible tablets in 6.8 phosphate buffer at $37.5^{\circ} \mathrm{C}$ (where $\mathrm{CC}$ is the croscarmellose, $\mathrm{SSG}$ is the sodium starch glycolate, and $\mathrm{CP}$ is the crospovidone)

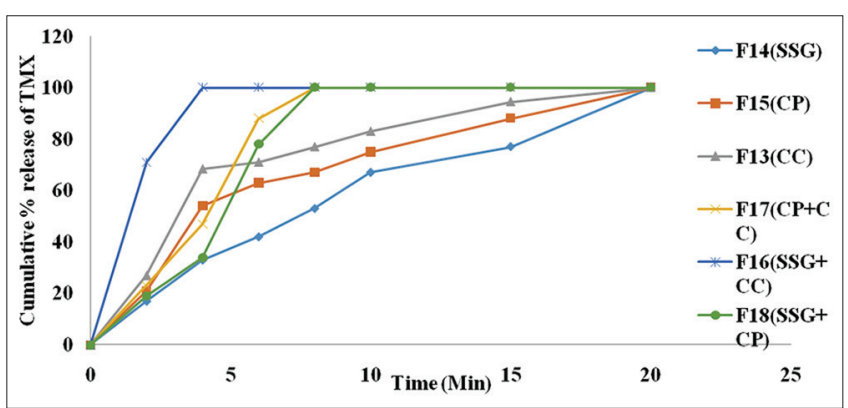

Fig. 8: Dissolution release profile of 1:7 solid dispersion formulas (F14-F18) orodispersible tablets in 6.8 phosphate buffer at $37.5^{\circ} \mathrm{C}$ (Where CC is the croscarmellose, SSG is the sodium starch glycolate, and $\mathrm{CP}$ is the crospovidone)

fastest disintegration time which is also the shortest among the rest of formulas which is contributed for dual disintegration synergistic action with rapid water intake of SSG and many different swelling and disintegration mechanisms of CC $[22,23]$.

\section{In vitro dissolution study}

Dissolution study is a crucial study for tablets that exhibit a fast release pattern especially orodispersible tablets in which this process attempt in a matter of seconds. According to the results, TMX exhibited a poor dissolution behavior and remains floated for most of the time of the test which is contributed to the higher lipophilicity nature. On the contrary, solid dispersion formulas showed a significant rapid, sharp release as 
Table 2: Powder evaluation of pure drug and solid dispersion powder

\begin{tabular}{llll}
\hline Powder & Angle of repose & Carr's index & Hausner's ratio \\
\hline Pure drug & $43.5 \pm 0.41$ & $38 \pm 0.81$ & $2.6 \pm 0.08$ \\
$1: 3$ SD & $20 \pm 0.81$ & $18.2 \pm 0.20$ & $1.22 \pm 0.01$ \\
$1: 5$ SD & $20.6 \pm 0.38$ & $16.8 \pm 0.16$ & $1.23 \pm 0.026$ \\
$1: 7$ SD & $22.7 \pm 0.32$ & $18.03 \pm 0.28$ & $1.25 \pm 0.024$ \\
$1: 10$ SD & $24.2 \pm 0.35$ & $12.67 \pm 0.53$ & $1.18 \pm 0.012$ \\
\hline
\end{tabular}

*Mean \pm SD, $n=3$

Table 3: In vitro disintegration time of the formulas prepared by solvent evaporation

\begin{tabular}{ll}
\hline Formula & Disintegration time (s) \\
\hline F1 & $8.4 \pm 0.31$ \\
F2 & $17.6 \pm 0.47$ \\
F3 & $9.06 \pm 0.09$ \\
F4 & $7.6 \pm 0.28$ \\
F5 & $8.2 \pm 0.2$ \\
F6 & $13.5 \pm 0.4$ \\
F7 & $8.3 \pm 0.23$ \\
F8 & $17.5 \pm 0.4$ \\
F9 & $9.1 \pm 0.23$ \\
F10 & $7.5 \pm 0.14$ \\
F11 & $8.25 \pm 0.2$ \\
F12 & $13.16 \pm 0.23$ \\
F13 & $7.58 \pm 0.11$ \\
F14 & $16.5 \pm 0.4$ \\
F15 & $8.5 \pm 0.42$ \\
F16 & $6.9 \pm 0.11$ \\
F17 & $7.58 \pm 0.11$ \\
F18 & $12.8 \pm 0.23$ \\
F19 & $7.5 \pm 0.08$ \\
F20 & $16.5 \pm 0.4$ \\
F21 & $8.5 \pm 0.4$ \\
F22 & $6.7 \pm 0.2$ \\
F23 & $7.3 \pm 0.14$ \\
F24 & $12.5 \pm 0.4$ \\
\hline
\end{tabular}

*Mean \pm SD, $\mathrm{n}=3$

a result of higher water solubility through solvent evaporation method. Figs 6-9 present the dissolution behavior of formulae (F1-F24).

\section{Factors affect dissolution profile of solid dispersion formulas}

\section{1-Effect of TMX to Soluplus ratio}

As can be seen from the results, the higher the proportion of Soluplus to TMX the sharper and faster dissolution profile which is remarkably significant for formulas (F19-F24) with 1:10 TMX to Soluplus ratio. Among them, F22 showed the fastest and complete dissolution profile which is within $<2 \min [14]$.

\section{2-Effect of type of superdisintegrant}

It can be noticed from the results that formulae with a single type of superdisintegrant, CC presented a faster and a sharper dissolution behavior between all formulae which is contributed to different types of disintegration mechanisms; by swelling and wicking that made it superior to the other superdisintegrant [21].

\section{3-Effect of mixed superdisintegrant}

Formulae with mixed types of superdisintegrants showed faster and a sharper dissolution profiles than a single superdisintegrant. Using a mixture of CC and SSG provided a superior dissolution time with $<2 \mathrm{~min}$. This behavior is due to a synergistic effect between CC and SSG that gives combined disintegration mechanisms of wicking and swelling of CC and high water absorption and swelling force of SSG to give enormous dissolution profile.

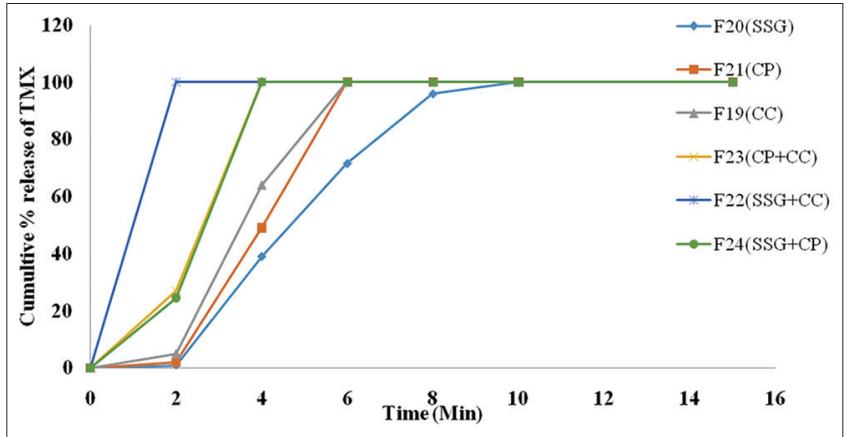

Fig. 9: Dissolution release profile of 1:10 solid dispersion formulas (F20-F24) orodispersible tablets in 6.8 phosphate buffer at $37.5^{\circ} \mathrm{C}$ (Where CC is the croscarmellose, SSG is the sodium starch glycolate, and CP is the crospovidone)

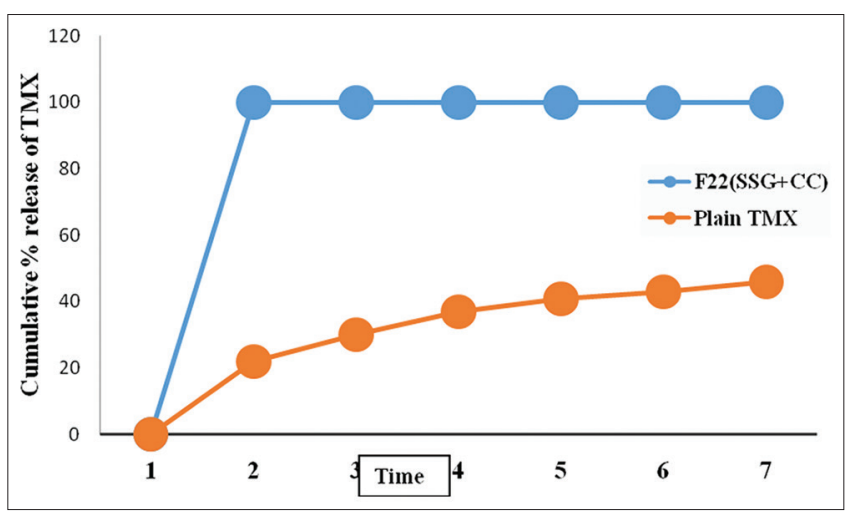

Fig. 10: Comparison in dissolution profile between the selected formula and plain tamoxifen citrate orodispersible tablets in 6.8 phosphate buffer at $37.5^{\circ} \mathrm{C}$

\section{Selection of the best formula}

According to the dissolution and the disintegration results, formula (F22) that contain a mixed proportion of CC and SSG of $5 \%$ of each one, was selected as the best formula with a faster disintegration time of $6.5 \mathrm{~s}$ and faster and sharper complete dissolution profile with $<2 \mathrm{~min}$.

\section{Comparison between the selected formula and plain TMX}

As presented in Fig. 10, formula F22 has faster and complete dissolution within 2 min which is highly significant than dissolution profile of plain TMX that showed slow with no complete dissolution. That may be explained by the preparation of solid dispersion using a solvent evaporation method can converts a crystalline nature of TMX to an amorphous state and enhances its water solubility, leads to an increase in its dissolution and disintegration rates.

\section{CONCLUSION}

TMX is an anticancer drug with a poor water solubility that was studied with Soluplus as a solubilizer which is, a novel polymeric carrier, using solid dispersion method through solvent evaporation technique then formulated as an orodispersible tablet dosage form. The saturation solubility of TMX was significantly increased through all ratios of Soluplus and was the highest with 1:10 ratio that increases its water solubility by 23 folds.

Orodispersible tablets were formulated using three different types of super disintegrants; CC, crospovidone, and SSG. Formula (F22) was selected as the best formula with a dissolution time $<2$ min which makes it succeed as an orodispersible tablet. Consequently, Soluplus is a promising polymeric solubilizer for poorly water-soluble drugs that can increase its solubility and enhances its bioavailability. 


\section{AUTHOR'S CONTRIBUTION}

Both authors have equally contributed.

\section{CONFLICTS OF INTEREST}

The authors declared that they have no conflicts of interest.

\section{REFERENCES}

1. Hortobagyi GN, de la Garza Salazar J, Pritchard K, Amadori D, Haidinger R, Hudis CA, et al. The global breast cancer burden: Variations in epidemiology and survival. Clin Breast Cancer 2005;6:391-401.

2. Ravikumara NR, Bharadwaj M, Madhusudhan B. Tamoxifen citrateloaded poly $(\mathrm{d}, 1)$ lactic acid nanoparticles: Evaluation for their anticancer activity in vitro and in vivo. J Biomater Appl 2016;31:1-18.

3. Beale, JM, Block JH. Wilson and Gisvold's Textbook of Organic Medicinal and Pharmaceutical Chemistry. $12^{\text {th }}$ ed. Philadelphia, PA, USA: Lippincott, Williams and Wilkins; 2011. p. 834.

4. Elnaggar YS, El-Massik MA, Abdallah OY. Self-nanoemulsifying drug delivery systems of tamoxifen citrate: Design and optimization. Int J Pharm 2009;380:133-41.

5. El-Leithy ES, Abdel-Rashid RS. Lipid nanocarriers for tamoxifen citrate/coenzyme Q10 dual delivery. J Drug Deliv Sci Technol 2017;41:239-50.

6. Meng F, Gala U, Chauhan H. Classification of solid dispersions: Correlation to (I) stability and solubility (II) preparation and characterization techniques. Drug Dev Ind Pharm 2015;41:1401-15.

7. Baghel S, Cathcart H, O'Reilly NJ. Polymeric amorphous solid dispersions: A review of amorphization, crystallization, stabilization, solid-state characterization, and aqueous solubilization of biopharmaceutical classification system class II drugs. J Pharm Sci 2016; 105:2527-44

8. Yadav Sh K, Veena M, Srinivas M. Solid dispersion techneque to enhance the solubility and dissolution rate of aripiprazole by fusion method. Int J Pharm Pharm Sci 2016;8:187-192.

9. Reginald-Opara JN, Attama A, Ofokansi K, Umeyor C, Kenechukwu F. Molecular interaction between glimepiride and soluplus-PEG 4000 hybrid based solid dispersions: Characterisation and anti-diabetic studies. Int J Pharm 2015;496:741-50.

10. Mohammadi G, Hemati V, Nikbakht MR, Mirzaee S, Fattahi A, Ghanbari $\mathrm{K}$, et al. In vitro and in vivo evaluation of clarithromycin-urea solid dispersions prepared by solvent evaporation, electrospraying and freeze drying methods. Powder Technol 2014;257:168-74.

11. Fule R, Amin P. Development and evaluation of lafutidine solid dispersion via hot melt extrusion: Investigating drug-polymer miscibility with advanced characterisation. Asian J Pharm Sci 2014;9:92-106.

12. Khan AW, Kotta S, Ansari SH, Sharma RK, Ali J. Enhanced dissolution and bioavailability of grapefruit flavonoid naringenin by solid dispersion utilizing fourth generation carrier. Drug Dev Ind Pharm 2015;41:772-9.

13. Huang Y, Dai WG. Fundamental aspects of solid dispersion technology for poorly soluble drugs. Acta Pharm Sin B 2014;4:18-25.

14. Shamma RN, Basha M. Soluplus ${ }^{\circledR}$ : A novel polymeric solubilizer for optimization of carvedilol solid dispersions: Formulation design and effect of method of preparation. Powder Technol 2013;237:406-14.

15. Dave V, Yadav RB, Ahuja R, Sahu AK. Formulation and evaluation of orally dispersible tablets of chlorpheniramine maleate by fusion method. Marmara Pharm J 2017;21:67-77.

16. Shankarrao KA, Mahadeo GD, Balavantrao KP. Formulation and in vitro evaluation of orally disintegrating tablets of olanzapine-2hydroxypropyl-beta-cyclodextrin inclusion complex. Iran J Pharm Res 2010;9:335-47.

17. Ge Z, Yang M, Wang Y, Shan L, Gao C. Preparation and evaluation of orally disintegrating tablets of taste masked phencynonate $\mathrm{HCl}$ using ion-exchange resin. Drug Dev Ind Pharm 2015;41:934-41.

18. Kimura SI, Uchida S, Kanada K, Namiki N. Effect of granule properties on rough mouth feel and palatability of orally disintegrating tablets. Int J Pharm 2015;484:156-62.

19. Homayouni A, Sadeghi F, Nokhodchi A. Preparation and characterization of celecoxib dispersions in soluplus ${ }^{\circledR}$ : Comparison of spray drying and conventional methods. Iran J Pharm Res 2015;14:35-50.

20. Shuai S, Yue S, Huang Q, Wang W, Yang J, Lan K, et al. Preparation, characterization and in vitro/vivo evaluation of tectorigenin solid dispersion with improved dissolution and bioavailability. Eur J Drug Metab Pharmacokinet 2016;41:413-22.

21. Rao NR, Patel T, Gandhi S. Development and evaluation of carbamazepine fast dissolving tablets prepared with a complex by direct compression technique. Asian J Pharm 2009;3:97-105.

22. Khairnar DA, Anantwar SP, Chaudhari CS, Shelke PA. Superdisintegrants: An emerging paradigm in orodispersible tablets. Int J Biopharm 2014;5:119-28.

23. Egla M, Abd Al hammid Sh N. Design zolmitryptan liquisolid orodispersible tablets and their in vitro evaluation. Int J Pharm Pharm Sci 2017;9:297-303. 